\title{
Características estruturais do pasto de capim-braquiária de acordo com a localização das fezes
}

\author{
Manoel Eduardo Rozalino Santos ${ }^{1}$, Dilermando Miranda da Fonseca ${ }^{2}$, Simone Pedro da \\ Silva ${ }^{3}$, Victor Valério de Carvalho ${ }^{4}$, Roberson Machado Pimentel ${ }^{4}$, Ronan Lopes Albino ${ }^{4}$ \\ ${ }^{1}$ Doutorando do Departamento de Zootecnia - Universidade Federal de Viçosa. \\ 2 Departamento de Zootecnia - Universidade Federal de Viçosa. \\ ${ }^{3}$ Mestranda do Departamento de Zootecnia - Universidade Federal de Viçosa. \\ ${ }^{4}$ Graduando em Zootecnia - Universidade Federal de Viçosa.
}

RESUMO - Objetivou-se avaliar o efeito da localização das fezes de bovinos sobre as características de perfilhos vegetativos e reprodutivos, a massa dos componentes da planta, a densidade volumétrica da forragem e a altura do pasto de Brachiaria decumbens, cv. Basilisk, manejado sob lotação contínua. O delineamento foi em blocos casualizados, com três repetições, em esquema de parcela subdivida, considerando parcelas os locais próximos e distantes das fezes e subparcelas as categorias de perfilhos vegetativos e reprodutivos. A massa de lâmina foliar viva (LFV) por perfilho em locais próximos às fezes $(0,14 \mathrm{~g})$ foi maior que nos locais distantes das fezes $(0,08 \mathrm{~g})$, contrariamente ao verificado para a composição de massa de lâmina foliar morta por perfilho. A massa de LFV nos perfilhos vegetativos $(0,15 \mathrm{~g})$ foi maior que nos perfilhos reprodutivos $(0,06 \mathrm{~g})$. Por outro lado, a massa de colmo $(0,38 \mathrm{~g})$ e de lâmina foliar morta $(0,20 \mathrm{~g})$ foi maior nos perfilhos reprodutivos. O peso dos perfilhos das plantas próximas às fezes foi maior $(0,58 \mathrm{~g})$ que daqueles distantes das fezes $(0,17 \mathrm{~g})$. Em locais próximos das fezes, o número de perfilhos vegetativos foi menor, enquanto o de perfilhos reprodutivos foi maior. Maiores massas de colmo verde, forragem verde e forragem total do pasto foram observados nos locais próximos das fezes, quando comparadas aos distantes. Mesmo resultado foi obtido para a altura do pasto. A estrutura do pasto de Brachiaria decumbens é modificada pela localização das fezes dos bovinos em pastejo. A deposição de fezes por bovinos constitui fator de heterogeneidade espacial da vegetação em pastagem.

Palavras-chave: altura do pasto, Brachiaria decumbens, massa de forragem, perfilho reprodutivo, perfilho vegetativo

\section{Structural characteristics of Brachiaria grass pasture according to the location of feces}

\begin{abstract}
The objective of this study was to evaluate the effect of the cattle feces location on the characteristics of vegetative and reproductive tillers, dry mass content in plant components, forage volumetric density and Brachiaria decumbens cv. Basilisk pasture height managed under continuous stocking. It was used a randomized block design with three repetitions in a split-plot scheme considering the plots the sites next and far from feces and the sub-plots were the vegetative and reproductive tiller categories. Dry mass content of live foliar blade (LFB) per tiller in sites near the feces (0.14 g) was higher than in the sites distant from the feces $(0.08 \mathrm{~g})$, opposing to what was verified for composition of dry matter of dead foliar blade per tiller. Content of LFB dry mass in vegetative tillers $(0.15 \mathrm{~g})$ was higher than in the reproductive tillers (0.06 g). On the other hand, composition in stem dry matter $(0.38 \mathrm{~g})$ and in dead foliar blade $(0.20 \mathrm{~g})$ were higher for reproductive tillers. Tiller weight of the plants near the feces was higher $(0.58 \mathrm{~g})$ than those far from the feces $(0.17 \mathrm{~g})$. On sites near the feces, the number of vegetative tiller was lower, while the number of reproductive tiller was higher. Higher contents of dry matter of the green stem, green forage and total forage of the pasture were observed on sites close to feces when compared to the far ones. The same result was obtained for the pasture height. The Brachiaria decumbens pasture structure is modified by the position of the cattle feces. Cattle feces droppings are a heterogeneous spatial factor of vegetation on grazing areas.
\end{abstract}

Key Words: Brachiaria decumbens, forage mass, pasture height, reproductive tiller, vegetative tiller 


\section{Introdução}

Em pastagens, é comum a existência de locais com maior frequência e/ou intensidade de desfolhação, devido, entre vários fatores, à seletividade de pastejo pelo animal. Isso acaba resultando na estrutura em mosaico do pasto, que tem implicações importantes na produção do ecossistema pastoril (Carvalho et al., 2009). Em verdade, a diversidade de microclimas na pastagem, decorrente da heterogeneidade do pasto, afeta a morfogênese da forrageira e a estrutura do pasto, que tem efeito no comportamento ingestivo, no consumo e no desempenho animal (Carvalho et al., 2009).

Nesse contexto, a deposição de fezes pelos ruminantes na pastagem influencia a variabilidade espacial da vegetação no pasto, uma vez que as fezes afetam a seletividade pelo animal e o crescimento da forrageira. Realmente, a presença de fezes provoca a rejeição das plantas em seu entorno pelos bovinos (Nolan et al., 1986; Willians \& Haynes, 1995), pode aumentar a disponibilidade de nutrientes no solo para o pasto (Marchesin, 2005) e criar áreas de solo descoberto, o que facilita a colonização por outras espécies vegetais (Dias-Filho \& Ferreira, 2008).

A presença de fezes, então, afeta a estrutura do pasto, entendida como o arranjo espacial dos componentes da parte aérea das plantas dentro de uma comunidade (Laca \& Lemaire, 2000). Essa estrutura, por sua vez, não é estática, e pode ser modificada durante o tempo por meio de novos processos inerentes e oriundos da interface entre a forrageira e o animal.

Uma das formas de compreender as mudanças na estrutura do pasto ocasionadas pelas fezes consiste na caracterização e avaliação de perfilhos individuais no pasto. Esses estudos reducionistas são necessários para uma pesquisa mais analítica e explicativa do ecossistema pastagem, embora esses conhecimentos gerados tenham que ser integrados em escalas superiores (Carvalho, 1997). Dessa forma, além de avaliações de perfilhos, também é relevante analisar o pasto por meio de características descritoras de sua estrutura, como a massa e a densidade de forragem e sua composição morfológica.
Assim, objetivou-se neste trabalho comparar as características de perfilhos vegetativos e reprodutivos, assim como a estrutura do pasto de Brachiaria decumbens, cv. Basilisk, manejado sob lotação contínua, em locais da pastagem de acordo com a localização das fezes depositadas naturalmente por bovinos.

\section{Material e Métodos}

Este trabalho foi conduzido de novembro de 2007 a maio de 2008 numa área de pastagem de Brachiaria decumbens cv. Basilisk (Stapf.) (capim-braquiária), estabelecida em 1997, com aproximadamente $10.000 \mathrm{~m}^{2}$, pertencente ao Setor de Forragicultura do Departamento de Zootecnia da Universidade Federal de Viçosa. A área experimental era constituída de três piquetes (unidades experimentais) de cerca de 0,30 ha, além de uma área reserva. O solo da área experimental é latossolo vermelho-amarelo de textura argilosa. A análise química do solo, realizada no início do período experimental, na camada 0 a $20 \mathrm{~cm}$, apresentou os seguintes resultados: $\mathrm{pH}$ em $\mathrm{H}_{2} \mathrm{O}: 5,4$; $\mathrm{P}: 1,5$ (Mehlich-1) e $\mathrm{K}: 88 \mathrm{mg} / \mathrm{dm}^{3} ; \mathrm{Ca}^{2+}: 1,88 ; \mathrm{Mg}^{2+}: 0,47 \mathrm{e} \mathrm{Al}^{3+}: 0,16 \mathrm{cmol}_{\mathrm{C}} / \mathrm{dm}^{3}$ (KCl $1 \mathrm{~mol} / \mathrm{L})$. Durante o período de avaliação, os dados climáticos foram registrados em estação meteorológica a aproximadamente $500 \mathrm{~m}$ da área experimental (Tabela 1).

A adubação fosfatada foi feita no dia 16 de janeiro de 2008, com a aplicação de $70 \mathrm{~kg} /$ ha de $\mathrm{P}_{2} \mathrm{O}_{5}$, na forma de superfosfato simples, em toda área experimental. A adubação nitrogenada, na forma de ureia, foi realizada em três aplicações de $50 \mathrm{~kg} / \mathrm{ha}$ de nitrogênio ao final da tarde de cada data de aplicação (16/1/2008, 26/2/2008 e 7/4/2008).

Desde novembro de 2007, os piquetes foram manejados sob lotação contínua com taxa de lotação variável a fim de manter a altura do pasto em cerca de $25 \mathrm{~cm}$. Para isso, a altura do pasto foi avaliada duas vezes por semana e foram utilizados bovinos machos em recria com peso médio de $200 \mathrm{~kg}$.

Foram avaliados dois locais na pastagem, um próximo e outro distante das fezes, bem como de duas categorias de perfilhos, quais sejam, perfilhos vegetativos e perfilhos

Tabela 1 - Temperatura média diária, insolação, precipitação pluvial total mensal e evaporação total mensal nos períodos de novembro de 2007 a maio de 2008

\begin{tabular}{lcccc}
\hline Mês & Temperatura média do ar $\left({ }^{\circ} \mathrm{C}\right)$ & Insolação (horas/dia) & Precipitação pluvial $(\mathrm{mm})$ & Evaporação $(\mathrm{mm})$ \\
\hline Novembro/2007 & 21,9 & 4,9 & 52,6 & 175,7 \\
Dezembro/2007 & 22,9 & 10,7 & 219,5 & 97,7 \\
Janeiro/2008 & 21,6 & 8,2 & 112,7 & 434,6 \\
Fevereiro/2008 & 22,7 & 8,5 & 239,2 & 67,1 \\
Março/2008 & 22,0 & 6,1 & 62,6 & 67,8 \\
Abril/2008 & 21,5 & 6,4 & 4,6 \\
Maio/2008 & 17,8 & 7,4 & 65,5 \\
\hline
\end{tabular}


reprodutivos. Considerou-se próximo das fezes o local imediatamente adjacente às fezes, enquanto o local distante foi aquele em que, num raio de cerca de 1 metro, não havia presença de fezes. Foram classificados como perfilhos vegetativos aqueles vivos, porém sem inflorescência. Os perfilhos vivos que continham inflorescência foram denominados reprodutivos. Adotou-se o delineamento em blocos ao acaso, com três repetições, em esquema de parcelas subdivididas, de modo que os locais na pastagem constituíram as parcelas e as categorias de perfilhos, as subparcelas.

No início de janeiro de 2008, o pasto de capim-braquiária foi infestado pela lagarta Mocis latipes, o que impediu a realização e continuidade das avaliações em campo, que haviam iniciado em meados de dezembro de 2007. Com a infestação da lagarta, retiraram-se os animais dos piquetes e fez-se aplicação do inseticida do grupo piretroide (Decis $25 \mathrm{EC}$ ) na dose de $200 \mathrm{~mL} / \mathrm{ha}$. Os piquetes foram novamente utilizados, sob pastejo e seguindo o mesmo manejo anterior, somente a partir de meados de fevereiro de 2008, época em que teve início a determinação das variáveis respostas. As avaliações foram mensais e findaram na primeira semana de maio de 2008.

Em cada piquete foram colhidas duas amostras de cada local avaliado (próximo e distante das fezes), uma constituída de 30 perfilhos vegetativos, e a outra, de 30 perfilhos reprodutivos. As amostras foram separadas em lâmina foliar verve, lâmina foliar morta e colmo verde. A região da lâmina foliar sem sinais de senescência (órgão de cor verde) foi incorporada à fração lâmina foliar verde. A região da lâmina foliar com amarelecimento e, ou, necrosamento do órgão foi incorporada à fração lâmina foliar morta. No caso dos perfilhos em estádio reprodutivo, suas inflorescências foram incorporadas à fração colmo verde. Nas duas categorias de perfilhos avaliadas, não houve participação de colmo morto. As subamostras dos componentes morfológicos de cada categoria de perfilho foram acondicionadas em sacos de papel identificados, que foram levados a estufa de ventilação forçada a $65^{\circ} \mathrm{C}$ por 72 horas e, em seguida, pesados. Com esses dados, calcularam-se a massa dos componentes morfológicos e o peso unitário de cada categoria de perfilho.

Para determinação da densidade populacional de perfilhos, foram colhidas seis amostras por piquete, metade próxima e metade distante das fezes, com corte rente ao solo de todos os perfilhos contidos no interior de um quadrado de $0,25 \mathrm{~m}$ de lado. Esses perfilhos foram acondicionados em sacos plásticos identificados e, em seguida, levados para o laboratório, onde foram quantificados e classificados. Os perfilhos vivos com inflorescência visível foram classificados como reprodutivos e os vivos sem a inflorescência visível foram denominados vegetativos.

A massa de forragem foi estimada mediante corte, rente ao solo, de todos os perfilhos contidos no interior de um quadrado de $0,16 \mathrm{~m}^{2}$, em três áreas representativas de cada local do pasto (próximo e distante das fezes) por piquete. Cada amostra foi acondicionada em saco plástico identificado e, no laboratório, pesada e subdividida em duas partes. Uma das subamostras foi pesada, acondicionada em saco de papel e colocada em estufa com ventilação forçada, a $65^{\circ} \mathrm{C}$, durante 72 horas, quando novamente foi pesada. A outra subamostra foi separada em lâmina foliar verde (LFV), colmo verde e material morto. A inflorescência e a bainha foliar verdes foram incorporadas à fração colmo verde. A parte da lâmina foliar que não apresentava sinais de senescência foi incorporada à fração lâmina foliar verde. As partes do colmo e da lâmina foliar senescentes e mortas foram incorporadas à fração material morto. Após a separação, os componentes das plantas de capim-braquiária foram pesados e secos em estufa de circulação forçada a $65^{\circ} \mathrm{C}$, por 72 horas. O somatório da massa de lâminas foliares verdes e colmos verdes correspondeu à massa de forragem verde.

As amostras de perfilhos vegetativos e reprodutivos não foram retiradas das amostras de massa de forragem do pasto porque possivelmente na área amostrada para determinação da massa de forragem $\left(0,16 \mathrm{~m}^{2}\right)$ não havia número de perfilhos reprodutivos suficientes para obtenção de amostra significativa. Além disso, quando as amostras de forragem são colocadas em saco plástico e levadas para o laboratório, é comum que algumas folhas mortas se desprendam do colmo dos perfilhos e, com isso, os perfilhos obtidos dessas amostras poderiam não ter seu peso e sua composição morfológica quantificados de maneira fidedigna.

A altura do pasto foi mensurada em 50 pontos por piquete, escolhendo-se aleatoriamente 25 pontos adjacentes às placas de fezes e 25 distantes delas. Para isso, usou-se uma régua graduada.

A densidade volumétrica da forragem e de seus componentes morfológicos, expressa em $\mathrm{kg} / \mathrm{cm}$.ha, foi calculada pela divisão da massa de forragem e da massa de seus componentes morfológicos pela altura do pasto em cada local, de acordo com a localização das fezes.

As análises dos dados experimentais foram feitas usando o Sistema para Análises Estatísticas - SAEG, versão 8.1(UFV, 2003). Para cada característica, foi realizada análise de variância e aplicado do teste $\mathrm{F}$ a fim de comparar os dois locais do pasto e as duas categorias de perfilhos. Na 
avaliação da massa dos componentes morfológicos e do peso por perfilho, adotou-se o esquema de parcela subdividida, considerando os locais do pasto (próximo e distante das fezes) como parcelas e as categorias de perfilhos (vegetativos e reprodutivos) como subparcelas. O delineamento foi em blocos ao acaso. Todas as análises estatísticas foram realizadas aplicando-se o nível de até 5\% de significância.

\section{Resultados e Discussão}

Para todas as características dos perfilhos individuais, não houve $(\mathrm{P}>0,05)$ interação entre categorias de perfilhos e proximidade com as fezes. A massa de lâmina foliar verde por perfilho em locais próximos foi maior que nos locais distantes das fezes. Padrão de resposta semelhante ocorreu quanto à massa de colmo verde por perfilho (Tabela 2). Dois fatores podem ter influenciado esses resultados: a mineralização do material orgânico fecal e a rejeição da forragem pelos bovinos nos locais adjacentes às fezes.

Primeiramente, houve condições favoráveis ao maior acúmulo de biomassa por perfilho nos locais próximos das fezes, o que resultou em maior desenvolvimento do colmo e maior número de lâminas foliares vivas por perfilho. O maior desenvolvimento do colmo é necessário para sustentação das lâminas foliares. De fato, a deposição de fezes está associada à melhoria das condições de fertilidade do solo, pois favorece a disponibilização de nutrientes às plantas (Braz et al., 2003; Marchesin, 2005). Além disso, a influência das fezes no crescimento do pasto pode ocorrer em área cinco vezes maior que aquela fisicamente coberta por placas de fezes (During \& Weeda, 1973).

Tabela 2 - Massa dos componentes morfológicos por perfilho em pastos de capim-braquiária avaliada de acordo com a localização das fezes

\begin{tabular}{lccc}
\hline \multirow{2}{*}{ Perfilho } & \multicolumn{3}{c}{ Localização das fezes } \\
\cline { 2 - 4 } & Próxima & Distante & Média \\
\hline Vegetativo & 0,19 & Lâmina foliar verde $(\mathrm{g})$ \\
Reprodutivo & 0,08 & 0,11 & $0,15 \mathrm{~A}$ \\
Média & $0,14 \mathrm{a}$ & 0,05 & $0,06 \mathrm{~B}$ \\
& & Lâmina foliar morta $(\mathrm{g})$ \\
Vegetativo & 0,05 & 0,24 & $0,15 \mathrm{~B}$ \\
Reprodutivo & 0,14 & 0,37 & $0,20 \mathrm{~A}$ \\
Média & $0,10 \mathrm{~b}$ & $0,30 \mathrm{a}$ & \\
& \multicolumn{3}{c}{$0,19 \mathrm{~B}$} \\
Vegetativo & 0,25 & Colmo verde (g) \\
Reprodutivo & 0,44 & 0,13 & $0,38 \mathrm{~A}$ \\
Média & $0,35 \mathrm{a}$ & $0,23 \mathrm{~b}$ \\
\hline
\end{tabular}

Para cada variável-resposta, médias seguidas por mesma letra minúscula na linha e maiúscula na coluna não diferem $(\mathrm{P}>0,05)$ pelo teste $\mathrm{F}$.
Outro fator relevante é a rejeição da forragem pelos bovinos no entorno das fezes (Willians \& Haynes, 1995). Com isso, locais próximos das fezes são pastejados com menor frequência em comparação a locais mais distantes. Justamente por isso locais distantes das fezes apresentaram menores massas de lâmina foliar verde e de colmo verde por perfilho. A rejeição da forragem próxima das fezes pelos bovinos se daria, inicialmente, pelo odor das fezes e, posteriormente, pela maior maturidade da planta (Nolan et al., 1986). Perfilhos menores, comumente encontrados nos locais distantes das fezes, possuem lâminas foliares de menor tamanho, que necessitam de colmo menos desenvolvido para sua sustentação.

Resultado inverso foi verificado para massa de lâmina foliar morta por perfilho, que foi maior em locais distantes das fezes (Tabela 2). Provavelmente, houve maior desfolhação dos perfilhos nesses locais, o que pode ter ocasionado estresse nesses perfilhos e maior senescência de suas folhas. Realmente, desfolhações intensas podem provocar redução no crescimento e morte de raízes, como consequência da falta de energia proveniente da fotossíntese (Briske, 1991).

Além disso, a menor massa de lâmina foliar morta por perfilho em locais próximos das fezes pode ser justificada pelo possível aumento na duração de vida de suas folhas. A maior disponibilidade de nutrientes oriundos da mineralização das fezes, como o nitrogênio, pode ter aumentado a duração de vida da folha e o número de folhas de perfilhos individuais (Garcez Neto et al., 2002). Contudo, essa justificativa é controversa, uma vez que a duração de vida da folha parece ser apenas ligeiramente afetada pela disponibilidade de nitrogênio e, frequentemente, o que se observa é o aumento nas taxas de senescência foliar sob condições de alta disponibilidade deste nutriente (Nascimento Jr. \& Adese, 2004).

Neste trabalho, não foram avaliadas as características químicas do solo nos locais próximos e distantes das fezes depositadas pelos bovinos. Mesmo assim, é possível que tenha ocorrido maior disponibilização de nutrientes nos locais adjacentes às fezes. Realmente, Marchesin (2005), em pastagem de Brachiaria brizantha cv. Marandu manejada sob oferta de forragem de $5 \%$, constatou que o $\mathrm{pH}$ do solo foi maior nos locais com fezes de bovinos, o que contribuiu para a disponibilidade de macro e micronutrientes e para a indisponibilidade de alumínio.

Nos perfilhos vegetativos, a massa de lâmina foliar verde foi superior $(\mathrm{P}<0,05)$ à dos perfilhos reprodutivos (Tabela 2), o que confere característica desejável ao perfilho vegetativo do ponto de vista forrageiro, uma vez que a lâmina foliar verde é o componente morfológico do pasto 
que possui melhor valor nutritivo (Santos et al., 2008). Maior número de folhas verdes implica maior produção de fotoassimilados, o que também seria vantagem no acúmulo de energia necessário para crescimento e desenvolvimento do perfilho. Por outro lado, a massa de lâmina foliar morta foi maior $(\mathrm{P}<0,05)$ nos perfilhos reprodutivos (Tabela 2$)$, nos quais a partição de reservas e fotoassimilados é destinada, prioritariamente, à produção de sementes em detrimento à síntese de novas folhas e as folhas já existentes (mais velhas) normalmente senescem.

A massa de colmo verde nos perfilhos reprodutivos também foi maior $(\mathrm{P}<0,05)$ que nos perfilhos vegetativos (Tabela 2). Em perfilhos reprodutivos de capim-braquiária, ocorre típico alongamento do colmo (Santos et al., 2009b). Do ponto de vista evolutivo, esse alongamento do colmo pode ter favorecido a propagação dessa espécie, já que proporciona maior facilidade para dispersão de suas sementes, que podem se desprender dos rácemos para novas áreas adjacentes. Além disso, a localização da inflorescência na parte superior do dossel facilita o consumo de sementes pelos ruminantes, que podem ser agentes para sua dispersão.

Considerando os resultados de massa de colmo verde e lâmina foliar verde (LFV) por perfilho já discutidos anteriormente, a relação LFV/colmo verde foi maior $(\mathrm{P}<0,05)$ nos perfilhos vegetativos e não diferiu entre as distâncias das fezes (Figura 1).

O perfilho reprodutivo possuiu maior peso $(\mathrm{P}<0,05)$ em comparação ao perfilho vegetativo (Figura 2a). Esse resultado era esperado, uma vez que o perfilho reprodutivo

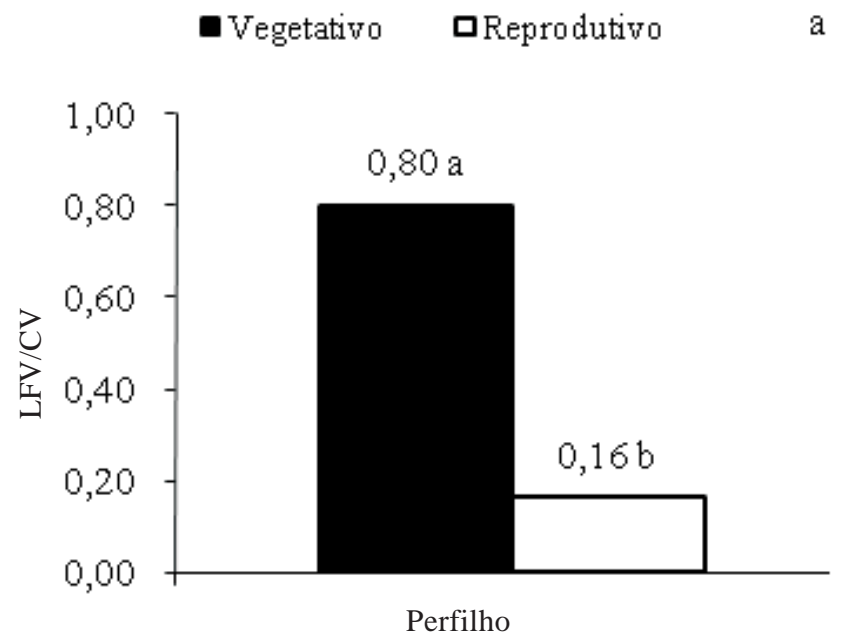

apresenta em geral estádio de desenvolvimento mais avançado e, por isso, possui maior número de fitômeros, resultando em maior massa do perfilho. Adicionalmente, o típico alongamento do colmo no perfilho em estádio reprodutivo contribui muito para seu maior peso.

O peso dos perfilhos localizados próximos das fezes foi maior $(\mathrm{P}<0,05)$ que o daqueles distantes das fezes (Figura 2b). O maior crescimento da forrageira e sua rejeição pelos bovinos nos locais adjacentes às fezes explicam esses resultados.

A densidade populacional de perfilhos vegetativos foi maior $(\mathrm{P}<0,05)$ em locais distantes das fezes, enquanto o número de perfilho reprodutivo foi maior $(\mathrm{P}<0,05)$ em locais próximos das fezes (Figura 3). O maior crescimento da forrageira, proporcionado pela deposição de nutrientes oriundos das fezes e também a rejeição do pasto pelo animal, resultaram em pastos mais altos próximos às fezes. Com isso, houve sombreamento de perfilhos vegetativos mais novos e de menor tamanho, que podem ter morrido. De fato, maior quantidade de assimilados é alocada para o crescimento de perfilhos já existentes em detrimento ao desenvolvimento de novos perfilhos em situação de sombreamento (Pedreira et al., 2001). Além disso, a rejeição do pasto pelo animal em locais próximos das fezes possibilitou o desenvolvimento dos perfilhos vegetativos em reprodutivos de acordo com o ciclo fenológico da gramínea.

A análise conjunta dos dados de peso e número de perfilhos vegetativos permite constatar a ocorrência da lei de compensação entre tamanho e densidade populacional

Médias seguidas de mesma letra não diferem $(\mathrm{P}>0,05)$ pelo teste $F$.

Figura 1 - Relação lâmina foliar verde/colmo verde de perfilhos (a) vegetativos e reprodutivos de capim-braquiária de acordo com a localização (b) das fezes de bovinos. 
de perfilhos (Yoda et al., 1963) nos locais próximos e distantes das fezes no mesmo pasto de capim-braquiária manejado sob lotação contínua. Segundo essa lei, pasto com plantas mais altas, comum nos locais adjacentes às fezes (Figura 4), apresentam perfilhos mais pesados, porém com menor densidade populacional. Ao contrário, em pastos com menor altura, comum nos locais distantes das fezes (Figura 4), é maior o número de perfilhos de menor peso. As mudanças dinâmicas e compensatórias nos tamanhos e nos números de perfilhos do pasto são ocasionadas, sobretudo, pela competição interespecífica por luz entre os perfilhos no dossel (Sbrissia \& Silva, 2008).

Em locais com fezes na pastagem de capim-braquiária, tanto o número (Figura 3) quanto o peso do perfilho reprodutivo (Figura 2) foram maiores e indicam um padrão de resposta semelhante entre essas variáveis. Em geral, os perfilhos foram mais pesados nos locais próximos das fezes (Figura 2), em virtude de seu maior desenvolvimento. Além disso, o número de perfilhos reprodutivos também foi maior nesses locais do pasto, pois a frequência de pastejo foi menor e, dessa maneira, muitos perfilhos vegetativos não tiveram seu meristema apical eliminado pelo pastejo, então, passaram à categoria de perfilho reprodutivo.

Passando da escala de perfilho para escala do pasto, constataram-se diferenças $(\mathrm{P}<0,05)$ na massa de colmo verde, forragem verde e forragem total entre os locais do pasto próximo e distante das fezes. Por outro lado, a massa de material morto não foi influenciada $(\mathrm{P}>0,05)$ pela localização das fezes. Também não foi encontrada diferença $(\mathrm{P}>0,05)$ na massa de lâmina foliar verde entre os locais do pasto (Tabela 3).
口Reprodutivo

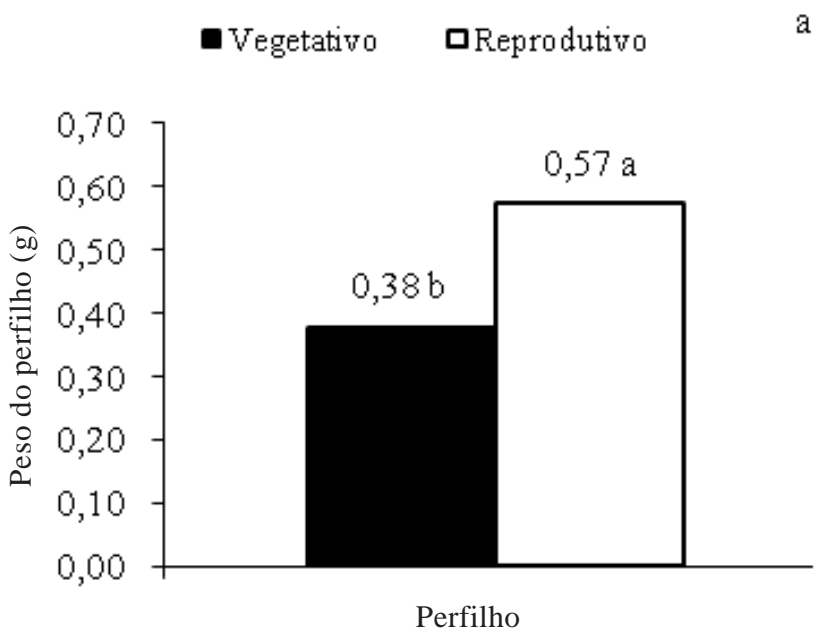

a

Médias seguidas por mesma letra não diferem $(\mathrm{P}>0,05)$ pelo teste $\mathrm{F}$.
Esses resultados podem ser explicados por dois fatores relacionados à deposição de fezes pelos bovinos. O primeiro é a rejeição da forragem pelos animais devido aos odores liberados pelas fezes. Dessa forma, o capim-braquiária teria mais tempo para cresces sem que os bovinos o consumissem, o que explica as maiores quantidades de massa de colmo verde, forragem verde e forragem total nesses locais. Já nos locais do pasto distantes das fezes, a frequência de pastejo é maior, fazendo com que as massas de forragem e de seus componentes morfológicos sejam em geral menores (Tabela 3).

O segundo fator, resultante da deposição das fezes no pasto, é a maior disponibilização e concentração de nutrientes no solo (Rodrigues et al., 2008), proporcionando desenvolvimento mais rápido das plantas. Isso justificaria as maiores massas de colmo verde, forragem verde e forragem total nos locais próximos em comparação aos locais distantes das fezes. Realmente, Marchesin (2005) constatou que o acúmulo de forragem na pastagem foi maior em pontos com a presença de bolo fecal $(685,82 \mathrm{~kg} / \mathrm{ha}$ de MS) que naqueles sem a presença de bolo fecal $(242,87 \mathrm{~kg} / \mathrm{ha}$ de MS).

A similaridade da massa de material morto nos locais do pasto próximas e distantes das fezes pode ser atribuída ao fato de que em locais próximos das fezes, o maior crescimento do pasto resultou em sombreamento e morte dos perfilhos mais jovens, em decorrência da competição por luz com os perfilhos mais velhos e de maior tamanho. Por outro lado, nos locais distantes das fezes, possivelmente, a frequência de pastejo foi maior e ocasionou a eliminação de meristemas apicais e gemas laterais, resultando também em morte de perfilhos. Esses fatores explicariam a ausência de efeito dos
Dróximo aDistante

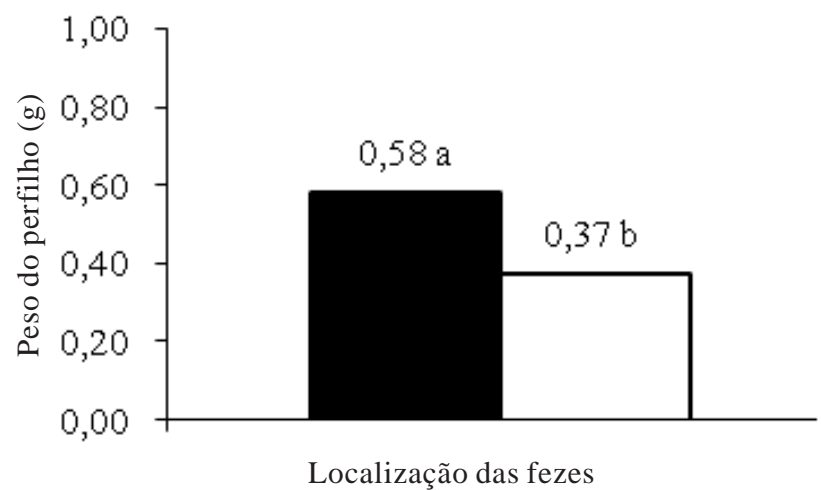

Figura 2 - Peso de perfilhos (a) vegetativos e reprodutivos em pastos de capim-braquiária de acordo com a localização (b) das fezes de bovinos. 
Tabela 3 - Matéria seca de forragem e dos componentes morfológicos da planta em pastos de capim-braquiária de acordo com a localização das fezes

\begin{tabular}{|c|c|c|c|c|c|}
\hline \multirow[b]{2}{*}{ Localização das fezes } & \multicolumn{5}{|c|}{ Matéria seca (kg/ha de MS) } \\
\hline & Lâmina foliar verde & Colmo verde & Forragem verde & Material morto & Forragem total \\
\hline Próximo & $1.650 \mathrm{a}$ & $2.285 \mathrm{a}$ & $3.935 \mathrm{a}$ & $3.468 \mathrm{a}$ & $7.403 \mathrm{a}$ \\
\hline Distante & $1.259 \mathrm{a}$ & $1.294 b$ & $2.553 b$ & $3.615 \mathrm{a}$ & $6.168 \mathrm{~b}$ \\
\hline
\end{tabular}

Para cada variável resposta, médias na coluna seguidas de mesma letra não diferem $(\mathrm{P}<0,05)$ pelo teste $\mathrm{F}$.

locais próximos e distantes das fezes sobre a massa de material morto do pasto (Tabela 3).

De acordo com os dados de composição morfológica de perfilhos individuais e do pasto nos locais avaliados, a massa de lâmina foliar verde foi maior e de lâmina foliar morta dos perfilhos, menor no local próximo das fezes (Tabela 2), porém, no pasto, as quantidades de massa de lâmina foliar verde e de material morto não foram influenciadas pela localização das fezes (Tabela 3). Essa aparente incoerência decorre do fato de que outros fatores além da massa dos perfilhos individuais em estádios vegetativos e reprodutivos também determinam a massa do pasto. Nesse sentido, variações no número de perfilhos vegetativos, reprodutivos e mortos também influenciam a massa dos componentes morfológicos do pasto. No caso da massa de material morto do pasto, um de seus principais determinantes é o número de perfilhos mortos (Santos et al., 2009a), que não foi avaliado neste trabalho.

Também foram encontradas diferenças $(\mathrm{P}<0,05)$ na altura do pasto decorrentes da localização das fezes (Figura 4). A maior altura do pasto próxima das fezes pode ser explicada pelos dois fatores citados, ou seja, pela rejeição da forragem pelos bovinos e pela maior disponibilidade de nutrientes
QDistante

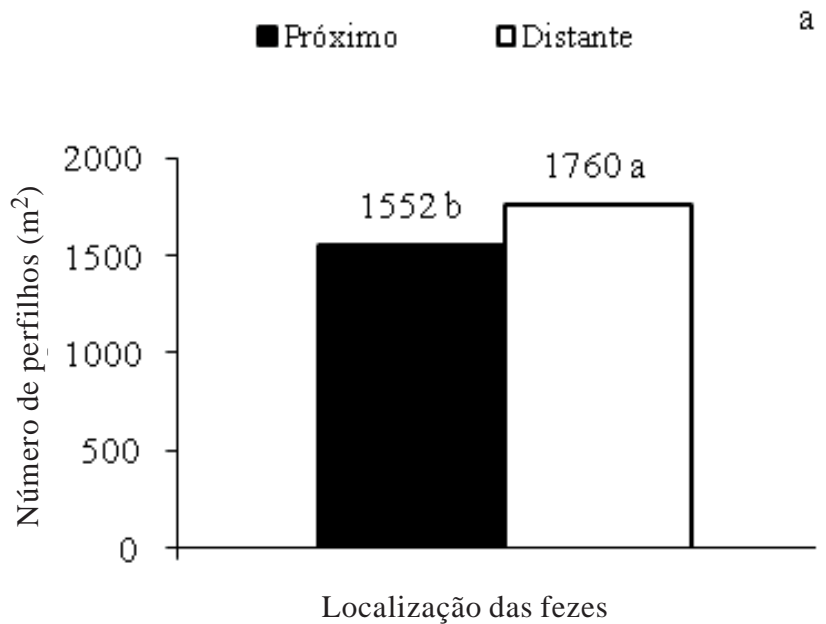

Localização das fezes nas proximidades das fezes, que aumenta a taxa de crescimento da forrageira.

A maior densidade volumétrica de forragem verde nos locais distantes das fezes (Figura 4) pode ser explicada pela redução acentuada da altura do pasto nesse local (Figura 4), o que compensou a elevação da massa de forragem verde próxima das fezes (Tabela 3). A densidade volumétrica de material morto foi menor $(\mathrm{P}<0,05)$ em locais próximos das fezes (Figura $4 \mathrm{~b}$ ). Como é calculada dividindo a massa de forragem no pasto pela sua altura, para a mesma massa de material morto nos locais do pasto (Tabela 3), obteve-se menor densidade volumétrica de material morto próximo das fezes porque a altura do pasto nesse local foi maior (figura 3).

Considerando que a distribuição espacial das fezes por bovinos em pastagens é heterogênea (Braz et al., 2003) e que, nos locais em que ocorre deposição de fezes pelos bovinos, as características estruturais de perfilhos e do pasto são diferentes, os resultados confirmam a existência de variação na estrutura do pasto. Essa variação aparece no decorrer do tempo de pastejo, de modo que alguns locais da pastagem (distantes das fezes) apresentam maior frequência de desfolhação, embora esse parâmetro não tenha sido

Médias seguidas por mesma letra não diferem $(\mathrm{P}>0,05)$ pelo teste $\mathrm{F}$.

Figura 3 - Número de perfilhos vegetativos (a) e reprodutivos (b) em pastos de capim-braquiária de acordo com a localização de fezes
de bovinos.

Figura 3 - Número de perfilhos vegetativos (a) e reprodutivos (b) em pastos de capim-braquiária de acordo com a localização de fezes
de bovinos.

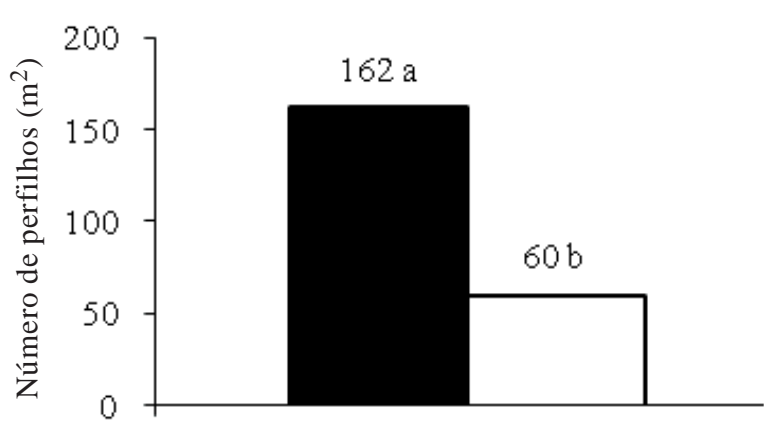

Localização das fezes 

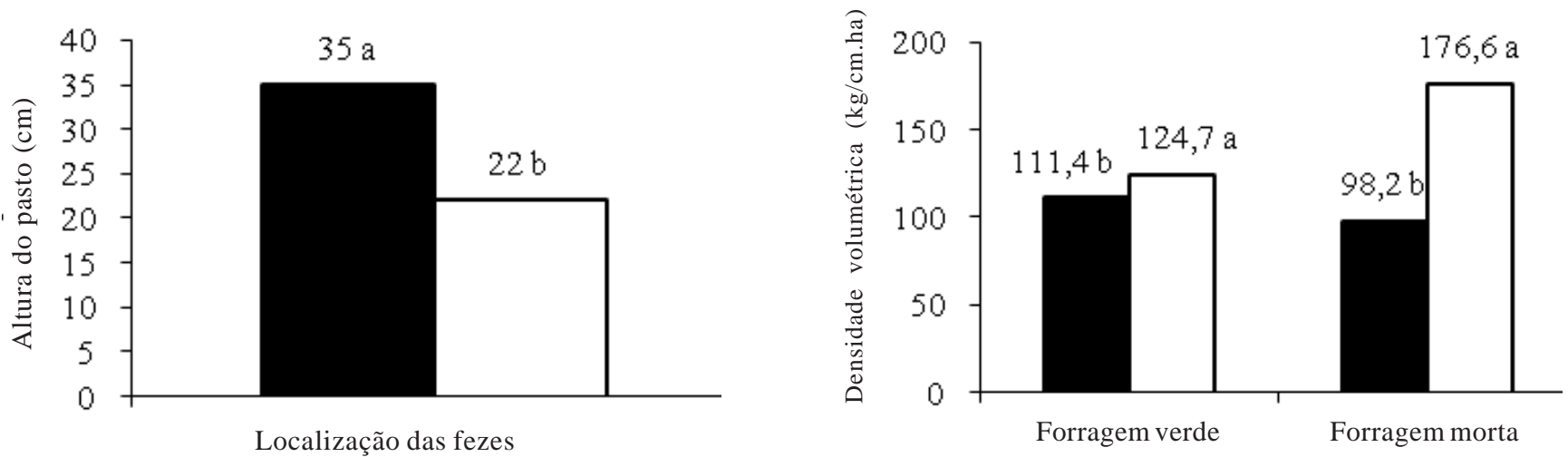

Médias seguidas por mesma letra não diferem $(\mathrm{P}>0,05)$ pelo teste $\mathrm{F}$.

Figura 4 - Altura do pasto (a) e densidade volumétrica (b) de capim-braquiária de acordo com a localização das fezes de bovinos.

avaliado neste trabalho. De fato, a vegetação numa pastagem é, por natureza, espacialmente heterogênea, pois existe grande amplitude de valores nas características descritoras da condição do pasto (Barthram et al., 2005), como altura, massa e densidade volumétrica de forragem.

As pesquisas para caracterizar a estrutura dos pastos tropicais são predominantemente relativas às variações verticais do relvado, ou seja, descrevem a forma como a forragem é disponibilizada do topo até sua parte inferior, enquanto a variação na estrutura horizontal raramente é avaliada ou considerada. Contudo, a estrutura horizontal é importante em todos os níveis da interação planta-animal, enquanto a vertical é relevante em níveis menores dessa interação (Carvalho et al., 2001).

Destaca-se que a diversidade de estruturas do pasto, resultante da deposição de fezes pelos bovinos, tende a ser benéfica para a pastagem, uma vez que forrageiras com características estruturais diferentes no mesmo pasto, portanto com fisiologias específicas, têm habilidades distintas para ocupar os vários nichos ecológicos, o que levaria à utilização dos recursos ambientais de forma mais completa e otimizada (Spehn et al., 2005). Contudo, estudos dessa natureza ainda são escassos com forrageiras tropicais e precisam ser realizados por períodos mais longos para confirmar essa hipótese.

\section{Conclusões}

A estrutura do pasto de Brachiaria decumbens é modificada pela localização das fezes de bovinos. Os perfilhos vegetativos possuem maior massa de lâmina foliar verde e menores massas de lâmina foliar morta e de colmos verdes em comparação aos perfilhos reprodutivos. Em pastos manejados sob lotação contínua, as massas de colmo verde, forragem verde e forragem total, a altura do pasto, o peso dos perfilhos e a densidade populacional de perfilhos reprodutivos são maiores nos locais próximos das fezes de bovinos. As densidades volumétricas de forragem verde e material morto e os números de perfilhos vegetativos são maiores nos locais do pasto distantes das fezes de bovinos. A deposição de fezes por bovinos constitui fator de heterogeneidade espacial da vegetação na pastagem.

\section{Referências}

BARTHRAM, E.; DUFF, G.T.I.; ELSTON, D.A. et al. Frequency distributions of sward height under sheep grazing. Grass and Forage Science, v.60, p.04-16, 2005.

BRAZ, S.P.; NASCIMENTO JR., D.; CANTARUTTI, R.B. et al. Caracterização da distribuição espacial das fezes por bovinos em uma pastagem de Brachiaria decumbens. Revista Brasileira de Zootecnia, v.32, n.4, p.787-794, 2003.

BRISKE, D.D. Development morphology and physiology of grasses. In; HEITSCHMIDT, R.K.; STUTH, J.W. (Eds.). Grazing management: a ecological perspective. Portland: Timber Press, 1991. p.85-108.

CARVALHO, P.C.F. A estrutura da pastagem e o comportamento ingestivo de ruminantes em pastejo. In: SIMPÓSIO SOBRE AVALIAÇÃO DE PASTAGENS COM ANIMAIS, 1., 1997, Maringá. Anais... Maringá: UEM, 1997. p.25-52.

CARVALHO, P.C.F.; MEZZALIRA, J.C.; FONSECA L. et al. Do bocado ao sítio de pastejo: manejo em 3D para compatibilizar a estrutura do pasto e o processo de pastejo. In: SIMPÓSIO DE FORRAGICULTURA E PASTAGENS, 7., 2009, Lavras. Anais... Lavras: UFLA, 2009. p.116-137.

CARVALHO, P.C.F.; RIBEIRO FILHO, H.M.N.; POLI, C.H.E.C. et al. Importância da estrutura da pastagem na ingestão e seleção de dietas pelo animal em pastejo. In: REUNIÃO ANUAL DA 
SOCIEDADE BRASILEIRA DE ZOOTECNIA, 38., 2001, Piracicaba. Anais... Piracicaba: ESALQ, 2001. p.883-871.

DIAS FILHO, M.; FERREIRA, J.N. Influência do pastejo na biodiversidade do ecossistema da pastagem. In: SIMPÓSIO SOBRE MANEJO ESTRATÉGICO DA PASTAGEM, 4., 2008, Viçosa, MG. Anais... Viçosa, MG: UFV, 2008. p.47-74.

DURING, C.; WEEDA, W.. Some effects of cattle dung on soil properties, pasture production, and nutrient uptake. New Zealand Journal of Agricultural Research, v.16, p.423-430, 1973.

GARCEZ NETO, A.F.; NASCIMENTO JR., D.; REGAZZI, A.J. et al. Respostas morfogênicas e estruturais de Panicum maximum cv. Mombaça sob diferentes níveis de adubação nitrogenada e alturas de corte. Revista Brasileira de Zootecnia, v.31, n.5, p.1890-1900, 2002.

LACA, E.A.; LEMAIRE, G. Measuring sward structure. In: T'MANNETJE, L.; JONES, R.M. (Eds.). Field and laboratory methods for grassland and animal production research. Wallingford: CABI Publishing, 2000. p.103-121.

MARCHESIN, W.A. Dinâmica de deposição de fezes em pastagem de Brachiaria brizantha submetida a intensidades de pastejo. 2005. 63f. Dissertação (Mestrado em Zootecnia) - Faculdade de Zootecnia e Engenharia de Alimentos, Pirassununga.

NASCIMENTO JR., D.; ADESE, B. Acúmulo de biomassa na pastagem. In: SIMPÓSIO SOBRE MANEJO ESTRATÉGICO DA PAStagem, 2., 2004, Viçosa, MG. Anais... Viçosa, MG: UFV, 2004. p.289-330.

NOLAN, T.; BJARNASON, V.; CONNOLY, J. et al. Animal/pasture relationships under mixed sheep/cattle grazing. In: GENERAL MEETING OF EUROPEAN GRASSLAND FEDERATION on “Grasslands facing the energy crisis”, 11., Portugal, 1986. Proceedings... Portugal, 1986. p.481-488.

PEDREIRA, C.G.S.; MELLO, A.C.L.; OTANI, L. O processo de produção de forragem em pastagens. In: REUNIÃO ANUAL
DA SOCIEDADE BRASILEIRA DE ZOOTECNIA, 38., 2001, Piracicaba. Anais... Piracicaba: ESALQ, 2001. p.772-807.

RODRIGUES, A.M.; CECATO, U.; FUKUMOTO, N.M. et al. Concentrações e quantidades de macronutrientes na excreção de animais em pastagem de capim-mombaça fertilizada com fontes de fósforo. Revista Brasileira de Zootecnia, v.37, n.6, p.990-997, 2008.

SANTOS, M.E.R.; FONSECA, D.M.; EUCLIDES, V.P.B. et al. Valor nutritivo da forragem e de seus componentes morfológicos em pastagens de Brachiaria decumbens diferida. Boletim da Indústria Animal, v.65, n.4, p.303-311, 2008.

SANTOS, M.E.R.; FONSECA, EUCLIDES, V.P.B. et al. Características estruturais e índice de tombamento de Brachiaria decumbens cv. Basilisk em pastagens diferidas. Revista Brasileira de Zootecnia, v.38, n.4, p.626-634, 2009a.

SANTOS, M.E.R.; FONSECA, D.M.; BALBINO, E.M. et al. Caracterização de perfilhos em pastos de capim-braquiária diferidos e adubados com nitrogênio. Revista Brasileira de Zootecnia, v.38, n.4, p.643-649, 2009b.

SBRISSIA, A.F.; DA SILVA, S.C. Compensação tamanho/densidade populacional de perfilhos em pastos de capim-marandu. Revista Brasileira de Zootecnia, v.37, n.1, p.35-47, 2008.

SPEHN, E.M.; HECTOR, A.; JOSHI, J. et al. Ecosystem effects of biodiversity manipulations in European grasslands. Ecological monographs, v.75, n.1, p.37-63, 2005.

UNIVERSIDADE FEDERAL DE VIÇOSA - UFV. SAEG - Sistema de análises estatísticas e genéticas. Versão 8.1. Viçosa, MG: 2003. (Apostila).

YODA, K.; KIRA, T.; OGAWA, H. et al. Intraspecific competition among higher plants. XI self-thinning in overcrowded pure stands under cultivated and natural conditions. Journal of Institute Polytechnics, Series D, v.14, p.107-129, 1963.

WILLIANS, P.H.; HAYNES, R.J. Effect of sheep, deer and cattle dung on herbage production and soil nutrient content. Grass and Forage Science, v.50, p.263-271, 1995. 